\title{
Effect of Si infiltration method on the properties of biomorphous SiC
}

\author{
V.S. Kiselov*, E.N. Kalabukhova, A.A. Sitnikov, P.M. Lytvyn, V.I. Poludin, \\ V.O. Yukhymchuk, A.E. Belyaev \\ V. Lashkaryov Institute of Semiconductor Physics, NAS of Ukraine \\ 41, prospect Nauky, 03028 Kyiv, Ukraine \\ *Corresponding author - fax: 38 (044)-525-59-40; e-mail: vit_kiselov@ukr.net
}

\begin{abstract}
Two types of wood-based biomorphous SiC composites with different microstructure were obtained by infiltration of carbon template with liquid or vapour silicon. The oak, pine, lilac, walnut, acacia woods available in Ukraine were used as the biological template in this work. SEM, optical and AFM data indicated that biomorphous $\mathrm{SiC}$ obtained by melt infiltration consists of crystalline phase of $3 \mathrm{C}-\mathrm{SiC}$, while that of vapor infiltration results in formation of crystalline and amorphous phases of $3 \mathrm{C}-\mathrm{SiC}$. The same results were obtained for infiltration of carbon fibers. Thus, it was suggested that the mechanism of $\mathrm{SiC}$ formation is governed by the infiltration method.
\end{abstract}

Keywords: biomorphous $\mathrm{SiC}$, Si infiltration, SEM, AFM, EPR, Raman scattering.

Manuscript received 11.12.08; accepted for publication 18.12.08; published online 02.03.09.

\section{Introduction}

Biomorphous composites $\mathrm{SiC} / \mathrm{Si}$ are known in the literature as ecoceramics - environment conscious ceramics [1-3]. Among the biomorphous composites, the porous $\mathrm{SiC}$ ceramics has been considered to be as one of the best candidate materials for orthopedic and dental implants due to their high level of biocompatibility, chemical inertness and mechanical strength [4-6]. Porous SiC has also a great potential for many industrial applications such as light ultra strong material in aerospace and motor-car industry, as well as a heat insulation material due to the low thermal expansion coefficient, small value of the relative density, mechanical strength, high chemical inertness, oxidation and corrosion resistance.

The objective of this work is to examine the effect of infiltration method on the parameters of wood-based biomorphous $\mathrm{SiC}$ composites. For this purpose, the biomorphous $\mathrm{SiC}$ was fabricated by infiltration of the carbon template with liquid or vapor silicon (Si).

\section{Technology preparation}

The technology process of biomorphous SiC preparation is well known [1-3]. The developed processing scheme for manufacturing the wood-based biomorphous $\mathrm{SiC}$ composite by the infiltration method used in this work is shown in Fig. 1.

The oak, pine, lilac, walnut, acacia woods available in Ukraine with average dimensions of $20-40 \mathrm{~mm}$ in diameter and height of $12 \mathrm{~mm}$ were used as the biological template in this study. At the initial stage, wood samples were pyrolized at $900{ }^{\circ} \mathrm{C}$ in an argon atmosphere. After pyrolysis, the carbon templates were reacted with liquid or vapour silicon produced by melting $\mathrm{Si}$ powder at $1500{ }^{\circ} \mathrm{C}$ in a graphite crucible in inert (Ar) atmosphere. For this purpose, the resistive furnace (REDMET 30) with graphite crucible was used. The carbon templates were placed into the graphite crucible along with well-milled $\mathrm{Si}$. The $\mathrm{Si} / \mathrm{C} /$ ratio was of $\psi=2$. Design of the graphite crucible allows fixing the position of the carbon templates so that only half of the carbon template was immersed into the $\mathrm{Si}$ melt providing the infiltration of that both with liquid and vapor $\mathrm{Si}$.

The spontaneous $\mathrm{Si}$ infiltration of the carbon templates was performed at $1500-1600{ }^{\circ} \mathrm{C}$ for $10-15 \mathrm{~min}$ in inert atmosphere ( $\mathrm{Ar}$ or $\mathrm{He}$ ). After that, the temperature was raised up to $1800-1900{ }^{\circ} \mathrm{C}$ and held for $30-60 \mathrm{~min}$. The final material of the reaction was a $\mathrm{SiC} / \mathrm{C}$ composite with a wood-like microstructure. An excess carbon was burn out in furnace in oxygen atmosphere at $900^{\circ} \mathrm{C}$ for 2 hours. 


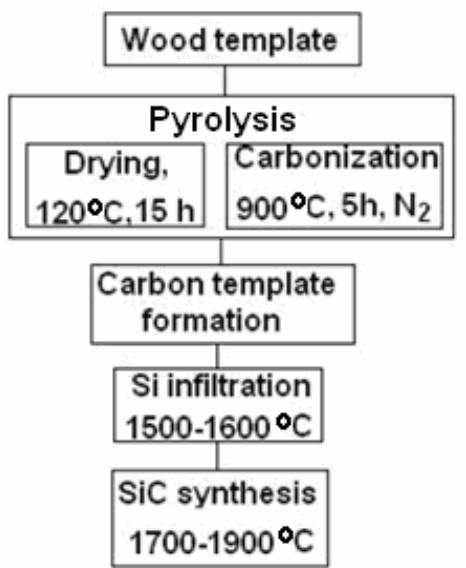

Fig. 1. Processing scheme for manufacturing biomorphous $\mathrm{SiC}$.

\section{Experimental results and discussion}

Optical and scanning electron microscopy (SEM), atomic force microscopy, Raman scattering spectroscopy and electron paramagnetic resonance (EPR) were used for compositional and structural analysis of biomorphous $\mathrm{SiC}$.

Surface and transverse cross section of the template were studied by SEM after infiltration and siliconization. Fig. 2 shows images of the transverse cross section of biomorphous $\mathrm{SiC}$ grown from walnut.

It was established that the mechanical properties, structure and color of biomorphous $\mathrm{SiC}$ depend on the carbon template infiltration method. The melt infiltration resulted in final material with high mechanical strength and green-brown color which was labeled as SiC-1 (see Fig. 2b), while the infiltration with $\mathrm{Si}$ vapor resulted in final material of white color with fibrous structure and

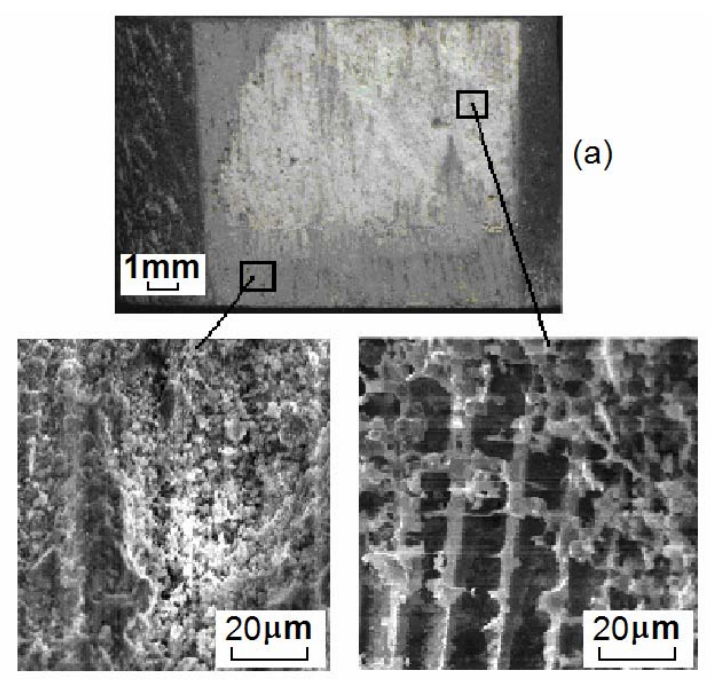

(b)

(c)

Fig. 2. Photo (a) and SEM images (b, c) of the transverse section of biomorphous $\mathrm{SiC}$ grown from walnut. was labeled as SiC-2 (see Fig. 2c). It was also found that the type of infiltration (with liquid or vapor $\mathrm{Si}$ ) depends on wood species. The fibrous structure of SiC-2 was clearly demonstrated when excess carbon was burn out. The fiber diameter is determined by tubular pore sizes in carbon template and varies from 1 to $30 \mu \mathrm{m}$. The fibers have a low mechanical strength and could be easily separated from the carbon template walls.

As it is seen from Figs 3 and 4, the fibers have flaked structure and ultrasonic treatment easily separates the flakes.

Raman spectra (RS) were taken with double grating spectrometer DFS-24 at room temperature. The 514.5$\mathrm{nm}$ line of an $\mathrm{Ar}^{+}$-laser was used for the excitation. The signal was registered with a cooled phototube working in photon counting mode in back scattering geometry. Fig. 5 shows RS observed in two types of biomorphous $\mathrm{SiC}$ grown from lilac. Analysis of RS peak frequencies observed in biomorphous $\mathrm{SiC}$ shows that biomorphous $\mathrm{SiC}-1$ should be attributed to the $3 \mathrm{C}$ polytype. Slightly higher values of LO and TO phonon bands (TO $796 \mathrm{~cm}^{-1}$ and LO $-972 \mathrm{~cm}^{-1}$ ) with respect to those in

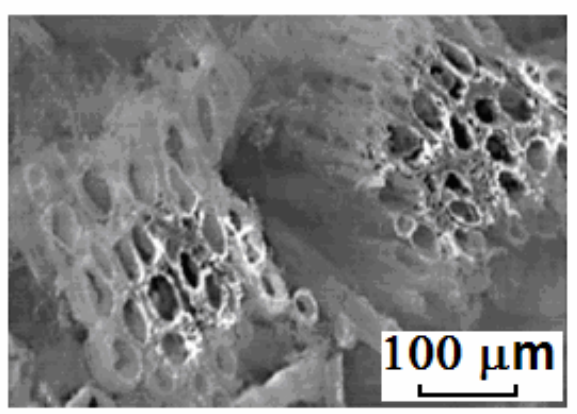

Fig. 3. Optical microscopy image of tubular fiber packages of the biomorphous $\mathrm{SiC}$ grown from lilac.

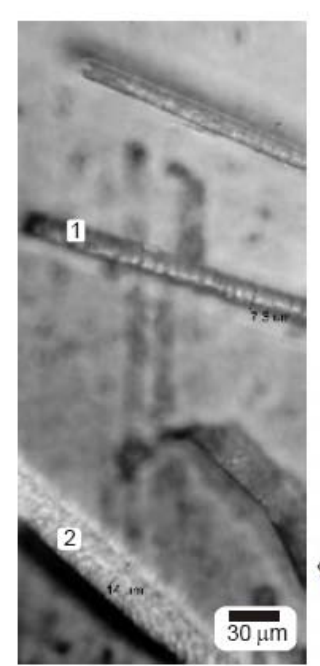

(a)

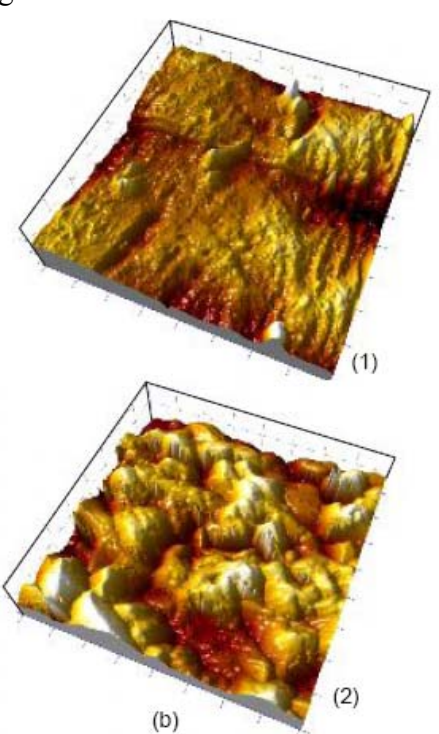

(b)
Fig. 4. Photomicrography (a) and AFM image (b) of $\mathrm{SiC}$ fibers grown from pine with scan size of $4 \times 4 \mu \mathrm{m}$ and $\mathrm{Z}$ range of $0.1 \mu \mathrm{m}$. 

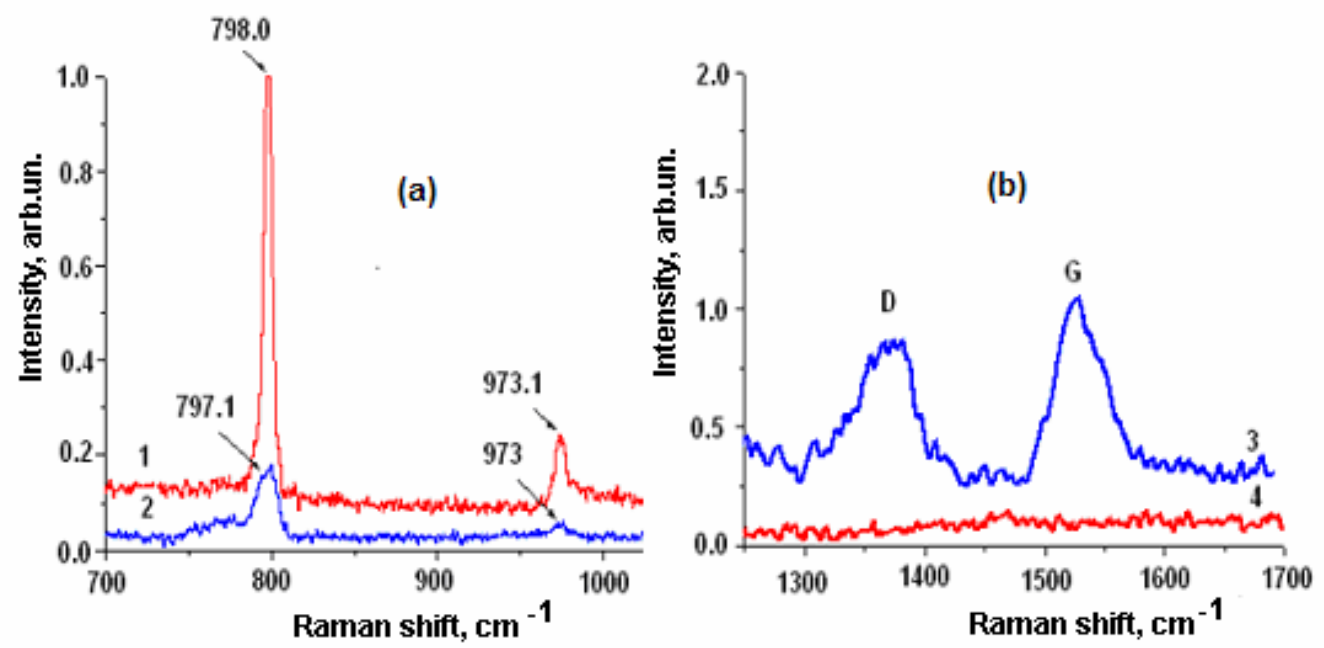

Fig. 5. RS of SiC-1 and SiC-2: a) RS of SiC observed in the C-C oscillation range, 1 - SiC-1, 2 - SiC-2, b) RS of SiC-1 observed in the $1300-1700 \mathrm{~cm}^{-1}$ range, 3 - as-synthesized $\mathrm{SiC}-1,4$ - carbon excess was burn out from SiC-1.

crystalline $3 \mathrm{C}-\mathrm{SiC}$ indicate that the biomorphous $\mathrm{SiC}$ is affected by compression. The LO and TO phonon bands in $\mathrm{RS}$ of $\mathrm{SiC}-2$ have lower intensities than in $\mathrm{SiC}-1$. In addition, the broad band centred at $765 \mathrm{~cm}^{-1}$ was observed in $\mathrm{RS}$ of $\mathrm{SiC}-2$ and could be attributed to the amorphous phase of $\mathrm{SiC}[7,8]$. Thus, $\mathrm{SiC}-2$ consists of crystalline and amorphous phase of $3 \mathrm{C}-\mathrm{SiC}$. It should be noted that depending on the $\mathrm{SiC}$ technology treatment the disordered (D) and graphitic (G) bands were observed in RS of SiC-1 (see Fig. 5b) due to clusters of carbon spots [9] which disappeared when excess carbon was burn out.

EPR spectrum was measured at $77 \mathrm{~K}$ and $9 \mathrm{GHz}$. In all the samples under EPR investigation, excess carbon was burnt out in oxygen atmosphere at $900^{\circ} \mathrm{C}$. The spectrum of biomorphous $\mathrm{SiC}-2$ with fibrous structure is shown in Fig. 6. There present is the $0.3 \mathrm{mT}$ wide single resonance with $g=2.0023 \pm 0.0002$, which is closer to the free electron value (2.0023) than to the usual carbon related EPR center value (2.0028) observed in amorphous carbon [10] and amorphous $\mathrm{SiC}$ material [11]. The fact that the $g$-value of the defect is closed to the free electron one indicates that unpaired electrons of carbon related defect in amorphous phase of $\mathrm{SiC}-2$ are delocalized due to formation of the carbon clusters. On the other hand, considering that SiC-2 contains crystalline phase of $3 \mathrm{C}-\mathrm{SiC}$, the observed EPR signal could be attributed to the carbon dangling bonds in crystalline phase of $3 \mathrm{C}-\mathrm{SiC}$. Our previous study of 3C$\mathrm{SiC}$ powders was shown that the $g$-factor of carbon dangling bonds in polycrystalline $3 \mathrm{C}-\mathrm{SiC}$ have $g=2.0023$ [12]. But in the light of the fact that EPR signal was not observed in $\mathrm{SiC}-1$ containing only crystalline phase of $3 \mathrm{C}-\mathrm{SiC}$ the first interpretation of the paramagnetic defect seems to be more plausible.
In order to determine the reaction mechanisms governing siliconization of carbon, we additionally applied impregnation of carbon fiber samples from the liquid or gas-phase of silicon. A SEM image of carbon fiber bunches after their processing are shown in Fig. 7. Faceted micro-crystals of the $\beta$-SiC (size 4-5 $\mu \mathrm{m}$ ) are observed on fibers in the case of liquid silicon

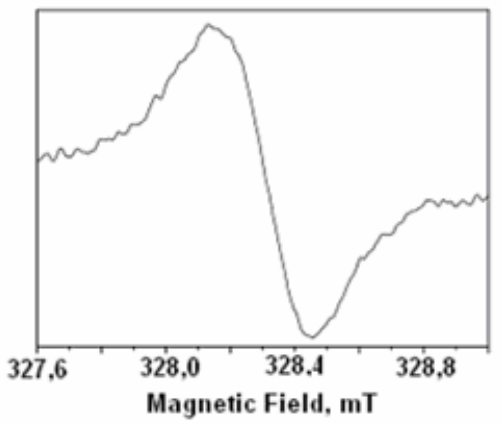

Fig. 6. EPR spectrum recorded at $9 \mathrm{GHz}$ and $77 \mathrm{~K}$ in biomorphous SiC-2.

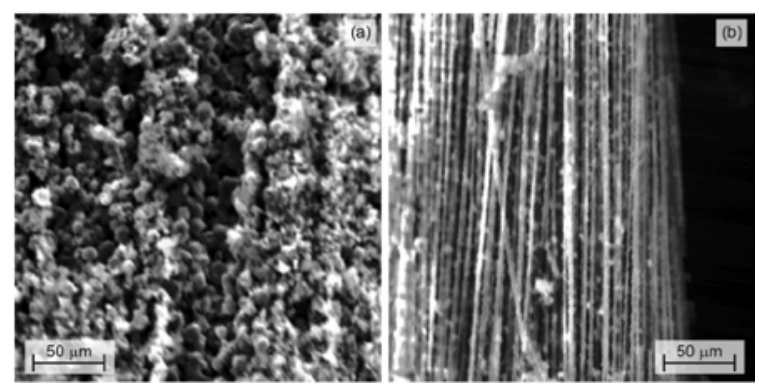

Fig. 7. SEM images of carbon fibers after $\mathrm{SiC}$ synthesis using liquid silicon (a) or its vapor (b). 
infiltration. These results are confirmed by the results obtained in $[13,14]$. Therefore, it could be suggested that the formation of the $\mathrm{SiC}$ precipitates are caused by the process of carbon dissolution in liquid Si (model via solution-precipitation) $[15,16]$. The infiltration with vapor Si resulted in smooth-faced, unstructured fibers consisting of amorphous $\mathrm{SiC}$ possibly due to the diffusion-controlled process $[17,18]$. Comparatively weak diffuse mass transport of Si takes place at gasphase infiltration, and only a thin layer of amorphous $\mathrm{SiC}$ is formed. These materials have different colors. Materials with microcrystalline structure have yellowbrown coloration and amorphous layers have white coloration.

\section{Conclusion}

The growth technology and parameters of wood-based biomorphous $\mathrm{SiC}$ ceramics obtained by infiltration with liquid or vapor silicon were examined. The relationship between infiltration method and microstructure of biomorphous $\mathrm{SiC}$ was established. It was found that structure and phase composition of the material depend on the carbon template infiltration method. Optical, EPR and SEM data indicate that the melt infiltration results in biomorphous $\mathrm{SiC}$ with crystalline phase of $3 \mathrm{C}$-SiC with the faceted morphology, while infiltration with $\mathrm{Si}$ vapor results in $\mathrm{SiC}$ with fibrous structure are provides both crystalline and amorphous phases of $3 \mathrm{C}-\mathrm{SiC}$. Thus, it was suggested that the mechanism of $\mathrm{SiC}$ formation is governed by the infiltration method.

\section{References}

1. P. Greil, T. Lifka, A. Kaindl // J. Europ. Ceram. Soc. 18, p. 1975-1983 (1998).

2. F.M. Varela-Feria, J. Martinez-Fernandez, A.R. de Arellano-Lopez, M. Singh // J. Europ. Ceram. Soc. 22, p. 2719-2725 (2002).

3. M. Presas, J.Y. Pastor, J. Llorca, A.R. Arellano Lopez, J. Martinez Fernandez, R. Sepulveda // Intern. J. Refractory Metals \& Hard Materials 24, p. 49-54 (2006).
4. S. Santavirta, M. Takagi, L. Nordsletten, A. Anttila, R. Lappalainen, Y.T. Konttinen // Arch Orthop. Trauma Surg. 118 (1-2), p. 89-91 (1998).

5. L. Nordsletten, A.K.M. Hogasen, Y.T. Konttinen, S. Santavirta, P. Aspenberg, A.O. Aasen // Biomaterials 17, p. 1521-1527 (1996).

6. A. de Carlos, J.P. Borrajo, J. Serra, P. Gonzalez, B. Leon // J. Mater. Sci.: Mater. Med. 17, p. 523529 (2006).

7. Properties of Silicon Carbide, edited by Gary L. Harris. IEE, INSPEC, the Institution of Electrical Engineers, London, 1995.

8. S. Klein, L. Houben, R. Carius, F. Finger, W. Fischer // J. Non-Crystal. Solids 352, p. 13761379 (2006).

9. J. Robertson, Amorphous carbon // Advanced in Physics 35, No. 4, p. 317-374 (1986).

10. H.J. von Bardeleben, J.L. Cantin, K. Zellama, A. Zeinert // Diamond and Related Materials 12, p. 124-129 (2003).

11. T. Christidis, M. Tabbal, S. Isber, M.A. El Khakani, M. Chaker // Appl. Surf. Sci. 184, p. 268-272, 2001.

12. E.N. Kalabukhova, S.N. Lukin and O.T. Sergeev // Fizika Tverd. Tela 35, p. 408 (1993) (in Russian)

13. C. Zollfrank, H. Sieber, Microstructure evolution and reaction mechanism of biomorphous SiSiC ceramics // J. Amer. Ceram. Soc. 88(1), p. 51-58 (2005).

14. M. Pyzalski, J. Bialoskorski, E. Walasek, Reaction between carbon fibres and molten silicon: heat determination using DTA // J. Therm. Anal. 31, p. 1193-1196 (1986).

15. R. Pampuch, E. Walasek, J. Bialoskorski, Mechanism of reactions in $\mathrm{Si}_{1}+\mathrm{C}_{\mathrm{f}}$ system // Ceram. Int. 13(1), p. 63-68 (1987).

16. P. Greil, T. Lifkaand, A. Kaindl, Biomorphic cellular silicon carbide ceramics from wood // J. Europ. Ceram. Soc. 18(14), p. 1961-1973 (1998).

17. E. Fitzer, R. Gadow, Fibre reinforced silicon carbide // Amer. Ceram. Soc. Bull. 65(2), p. 326335 (1986).

18. H. Zhou, R.N. Singh, Kinetics model for the growth of silicon carbide by the reaction of liquid silicon with carbon // J. Amer. Ceram. Soc. 78(9), p. 2456-2462 (1995). 